\title{
Usage frequencies of complement-taking verbs in Spanish and English: Data from Spanish monolinguals and Spanish-English bilinguals
}

\author{
Paola E. Dussias \\ Penn State University, University Park, Pennsylvania \\ Alejandra Marful \\ Universidad de Granada, Granada, Spain \\ CHIP GERFEN \\ Penn State University, University Park, Pennsylvania \\ AND \\ María Teresa Bajo Molina \\ Universidad de Granada, Granada, Spain
}

\begin{abstract}
Verb bias, or the tendency of a verb to appear with a certain type of complement, has been employed in psycholinguistic literature as a tool to test competing models of sentence processing. To date, the vast majority of sentence processing research involving verb bias has been conducted almost exclusively with monolingual speakers, and predominantly with monolingual English speakers, despite the fact that most of the world's population is bilingual. To test the generality of competing theories of sentence comprehension, it is important to conduct cross-linguistic studies of sentence processing and to add bilingual data to theories of sentence comprehension. Given this, it is critical for the field to develop verb bias estimates from monolingual speakers of languages other than English and from bilingual populations. We begin to address these issues in two norming studies. Study 1 provides verb bias norming data for 135 Spanish verbs. A second aim of Study 1was to determine whether verb bias estimates remain stable over time. In Study 2, we asked whether Spanish-English speakers are able to learn verb-specific information, such as verb bias, in their second language. The answer to this question is critical to conducting studies that examine when, during the course of sentence comprehension, bilingual speakers exploit verb information specific to the second language. To facilitate cross-linguistic work, we compared our verb bias results with those provided by monolingual English speakers in a previous norming study conducted by Garnsey, Lotocky, Pearlmutter, and Myers (1997). Our Spanish data demonstrated that individual verbs showed significant similarities in their verb bias across the 3 years of data collection. We also show that bilinguals are able to learn the biases of verbs in their second language, even when immersed in the first language environment. Appendixes $\mathrm{A}-\mathrm{C}$, containing the bilingual norms discussed in the article, may be downloaded from http://brm.psychonomic -journals.org/content/supplemental.
\end{abstract}

Studies of sentence comprehension that have employed different methodologies, tasks, and modes of language processing converge on the conclusion that a verb's subcategorization frame and subcategorization frequency influence reading speed and processing difficulty during sentence comprehension (e.g., Garnsey, Pearlmutter, Myers, \& Lotocky, 1997; Hare, McRae, \& Elman, 2003; MacDonald, 1994; MacDonald, Pearlmutter, \& Seidenberg, 1994a, 1994b; Trueswell, Tanenhaus, \& Kello, 1993; Wilson \& Garnsey, 2009). The term subcategorization frame denotes the order and category of the constituentsfor example, noun phrase (NP), prepositional phrase (PP), adverbial phrase (AdvP), complementizer phrase (CP) co-occurring with particular verbs. Thus, believe can occur in the slots in one of the following subcategorization frames: NP_ NP (John believes the story); NP_CP (John believes that the story was true); NP_ PP (John believes in Mary); or NP_AdvP (John believes so). Subcategorization frequency - also referred to in the psycholinguistic literature as verb bias - refers to a verb's preferential subcategorization frame. In the example above, believe not only subcategorizes for different types of complements, but also appears with each complement with different probabilities. According to some sources (e.g., Gahl, Jurafsky, \& Roland,

P. E. Dussias, pdussias@psu.edu 
2004; Garnsey, Pearlmutter, et al., 1997; Wilson \& Garnsey, 2009), it is twice as likely to be followed by a subordinate clause than by a direct object (DO) complement. Because of this, believe is said to have a clause bias or a sentential complement (SC) bias.

Increasingly, research on reading comprehension demonstrates that verb bias can ease the difficulty encountered during the processing of particular types of syntactic constructions. The evidence has come from studies where participants experienced a processing advantage when presented with sentences in which a verbal complement was congruent with the verb's preferred continuation, relative to cases where the complement was incongruent (e.g., Gahl et al., 2003; Garnsey, Pearlmutter, et al., 1997; Trueswell et al., 1993; Wilson \& Garnsey, 2009). For example, it has long been known that passive constructions such as The cow was kicked by the donkey are generally harder to comprehend than corresponding active transitive sentences (St. John \& Gernsbacher, 1998), break down more easily under processing stress (Miyake, Carpenter, \& Just, 1994), and are difficult to process for patients with certain types of aphasia (Bates, Friederici, \& Wulfeck, 1987; Druks \& Marshall, 1995; Friederici \& Graetz, 1987; Luzzatti et al., 2001). However, Gahl et al. (2003) showed that passive sentences with verbs that are preferentially passive facilitated performance in a group of aphasic patients, suggesting that comprehension processes are modulated by the match or mismatch between syntactic structure and verb bias.

One key distinguishing feature of two of the most prominent models of sentence processing is the role that lexically encoded information, such as verb bias information, plays in guiding initial syntactic analysis. Although there is a general consensus that verb bias comes into play at some point during sentence comprehension, a question that has been at the center of a lively debate in the sentence processing literature concerns whether verb bias affects initial processing decisions, as proposed by supporters of constraint-based lexicalist accounts of sentence processing (e.g., Garnsey, Pearlmutter, et al., 1997; MacDonald et al., 1994a, 1994b; Trueswell et al., 1993), or whether it comes into play only during the reanalysis stage, a position taken by proponents of modular two-stage theories of parsing (e.g., Ferreira \& Henderson, 1990; Frazier, 1987; Frazier \& Rayner, 1982; Kennison, 2001, 2009; Rayner, Carlson, \& Frazier, 1983). Recent evidence in favor of the first view comes from a study involving the manipulation of verb bias and syntactic frame. Wilson and Garnsey (2009) presented participants with sentences in which verbs that subcategorized for both a DO and an SC, with strong preference for one over the other, were followed by one or the other complement. The crucial test was whether a DO preceded by an SC bias verb would trigger reanalysis, a finding not predicted by two-stage models on the grounds that the parser initially favors syntactically simpler (i.e., DO) structures. Contrary to the prediction of modular models, Wilson and Garnsey found that sentences with DO complements were not uniformly easier to process; rather, initial processing was facilitated when the verbal complement matched the reader's expectations about the likely complement for that verb, suggesting that usage-based and exposure-based factors guide readers' initial comprehension.

By contrast, other studies provide evidence for twostage models of sentence comprehension. These models presume that during the first stage of processing, decisions are driven by syntactic or grammatical information alone. If the resulting interpretation is inconsistent with late-arriving information in the sentence, a second stage revises the interpretation using other sources of information, including verb-specific information (Frazier, 1987, 1990; Frazier \& Clifton, 1996; Frazier \& Fodor, 1978). A recent study by Kennison (2009) presents interesting evidence supporting the view that verb information affects later, but not earlier, stages of processing. Kennison performed two types of statistical analyses on data that replicated prior work by Trueswell et al. (1993), which found support for the early use of verb-specific information. An item-by-item correlational analyses (the same analysis employed in Trueswell et al., 1993) showed evidence that readers used verb bias early during processing, but participant-by-participant regressions led to the opposite conclusion. Crucially, the pattern of processing observed was most consistent with two-stage models of sentence comprehension, which called into question previous evidence in favor of the proposal that readers use multiple sources of information, including verb bias, to constrain initial sentence interpretation.

Within sentence processing research, the availability of verb bias norms has been critical for testing the predictions of the various models. However, as should be clear from the brief discussion presented above, the interpretation of the results has been contentious. Findings that have been taken to reflect early influence of lexical information on syntactic decisions can also be explained in terms of reanalysis processes. This scenario is complicated by the recent evidence suggesting that different statistical analyses produce competing results (Kennison, 2009). To determine which sentence processing model best characterizes the cognitive architecture that underlies the ability to construct syntactic representations in real time, we need to combine existing theoretically sophisticated experimentation with online methods and statistical analyses that allow us to unambiguously distinguish earlier- from laterstage processes of syntactic parsing. Until such methods are developed, converging evidence from cross-linguistic studies of monolingual sentence processing, as well as studies investigating sentence processing with different populations (e.g., bilingual populations), are critical for the construction of models of syntactic processing and for empirically testing the claims of each model.

Until now, such testing has come primarily from studies with monolingual speakers and, predominantly, from studies with monolingual English speakers. In recent years, the recognition that more individuals are bilingual than monolingual has led to an explosion of studies investigating the way in which bilinguals negotiate the presence of two languages in a single mind. Within bilingual research, some scholars study bilingualism because of its implications for pedagogical and clinical purposes; others em- 
ploy bilingualism as a tool to uncover important aspects of language function that may be otherwise obscured by studying individuals who speak only one language (e.g., Abutalebi, Cappa, \& Perani, 2005: Blumenfeld \& Marian, 2005; Dussias, 2003; Dussias \& Sagarra, 2007; FrenckMestre \& Pynte, 1997; Kroll \& de Groot, 2005; Kroll \& Stewart, 1994; Macizo \& Bajo, 2006; Marian \& Spivey, 2003; Sánchez-Casas, García-Albea, \& Davis, 1992; Stowe \& Sabourin, 2005; van Hell \& de Groot, 2008; Weber \& Paris, 2004). We illustrate the logic of the latter approach with the following example. One widely accepted view of bilingual lexical access is its nonselective nature (e.g., Jared \& Kroll, 2001; Schwartz, Kroll, \& Diaz, 2007; van Hell \& Dijkstra, 2002). In lexical decision and naming tasks, even bilinguals who are highly proficient in the second language (L2) are faster to respond to cognates (words that have similar form and meaning across two languages) than to noncognate controls, suggesting that bilinguals nonselectively activate orthographic and phonological codes in the two languages. In addition, recent evidence by Schwartz and Kroll (2006) indicates that the effects of cross-language activation at the lexical level can persist when cognates are embedded in sentence contexts (see also Duyck, van Assche, Drieghe, \& Hartsuiker, 2007; Elston-Güttler, Gunter, \& Kotz, 2005; Libben \& Titone, 2009; van Hell \& de Groot, 2008). The findings from these studies point to an important fact regarding bilingual language processing: The mere presence of language cues in a sentence (i.e., the knowledge that sentences will be presented entirely in the L2) is not sufficient to constrain nonselectivity of the nontarget first language (L1), at least in the case of cognates. Given the high activation of cognates during bilingual language processing, it should be possible to examine how cognate verbs with different verb biases in the bilingual's two languages impact L2 processing. From a theoretical standpoint, by manipulating the cognate status of verbs, it should be possible to identify the degree to which the ability to use the L2 in a manner that resembles that of native speakers depends on the relative activation of the L1 at the lexical level. The form of this interaction is critical not only for understanding the processes of bilingual comprehension, but more generally for understanding the role of lexical constraints in theories of sentence processing.

Because verb bias provides a crucial testing ground for competing theories of sentence processing, it is critical for the field to develop verb bias norms in numerous languages. As our knowledge about the factors that modulate syntactic parsing expands, we need an increasingly rich set of norms in order to probe the emerging theoretical questions raised by the different models of sentence processing. With this in mind, we report the results of two norming studies. In Study 1, the usage frequencies of 135 Spanish verbs were collected. Using verb bias data derived from normative studies to test competing models of sentence comprehension presupposes that norming results are consistent across time. To our knowledge, no study to date has explicitly addressed this question. Ensuring that verb-specific biases are robust is important, because past studies have shown the verb bias estimates are affected by a number of variables, including the method used to gather the data (e.g., sentence completion tasks or corpus-based approaches), the method used to compute verb bias (e.g., absolute frequency or relative frequency), and the specific senses of a verb (e.g., when "conclude" is followed by a DO, it usually means "to bring to an end"; however, if followed by a subordinate clause, it can mean "to arrive at an end by reasoning"; for an extensive discussion, see Gahl et al., 2004; Hare, McRae, \& Elman, 2004). In the present study, we examine the stability of verb bias estimates over time by collecting Spanish verb norms across 3 years. To facilitate comparisons between studies involving different languages, as well as studies examining how verb bias information in each of a bilingual's languages affects sentence processing in the $\mathrm{L} 1$ and the $\mathrm{L} 2,81$ of the 135 Spanish verbs were translations of the English verbs used in a norming study of American English conducted by Garnsey, Lotocky, Pearlmutter, and Myers (1997).

To gain insight into whether bilinguals are able to learn verb bias information in their L2, Study 2 reports the usage frequencies of 130 English verbs, obtained from a group of highly proficient Spanish-English bilinguals. The question of whether L2 speakers are ever able to learn verb information specific to the L2 is relevant because this information is learned implicitly, from direct exposure to the L2. Given that L2 learners often learn the L2 while being immersed in the L1 environment, and because verb bias information is not explicitly taught in language classrooms, one critical question is whether in this context, learners are able to extract verb bias information from the input. A second goal of Study 2 is to examine the strategies that bilinguals use when verb bias information in the L2 has not been learned. One logical possibility is that bilinguals transfer information from the L1 to the L2. Another option is that bilinguals opt for assigning the structurally simplest complement (e.g., a DO complement) to a verb. By examining the responses that bilinguals provide in a norming study, we can begin to provide some tentative answers to this question. These answers could, in turn, shed additional light on critical debates in the literature.

There are multiple ways to assess verb bias. In simple terms, one can break the problem down into two general approaches: norming approaches, as exemplified by our sentence completion task, and corpus-based approaches (e.g., Gahl et al., 2004; Hare et al., 2004; Roland et al., 2000), which assess bias through patterns of use across a large database of speakers and (potentially) genres. Both approaches are important and, optimally, should converge on similar results. Here, we have opted for a sentence completion approach. This choice is especially relevant for our purposes, given that such a strategy allows us to target specific populations of speakers, such as fluent Spanish-English bilinguals, for whom biases might be affected in particular ways related to their bilingualism, and who might thus depart in their bias preference patterns from the biases found for monolingual speakers of each language. To our knowledge, the corpus literature lacks language corpora consisting of data specifically culled from Spanish-English bilinguals. Thus, by using a single method, the sentence completion task, we can provide 
methodological consistency in our collection of norming data for Spanish monolinguals and Spanish-English bilinguals.

\section{STUDY 1 \\ Monolingual Spanish Speakers}

\section{Method}

Participants. A total of 575 monolingual speakers of Peninsular Spanish participated in the norming study. Participants were recruited over the course of 3 years. They were students in the Department of Psychology at the University of Granada (Spain) and received course credit for their participation. All participants reported having minimal or no knowledge of an L2.

Materials. Eighty-one verbs were selected from a list of 100 English verbs used in a norming study conducted by Garnsey, Lotocky, et al. (1997; henceforth, the Garnsey et al. norms). The remaining 19 verbs from the Garnsey et al. norms were excluded, because the syntactic frame of the Spanish verb does not allow the SC option that is permitted in English. For example, print in English accepts both a DO (e.g., "The student printed the paper") and an SC (e.g., "The newspaper that printed the news was good"), but Spanish allows only the DO option (e.g., "El estudiante imprimió el trabajo," but not "El periódico imprimió que la noticia era buena").

In the literature, the Garnsey et al. norms have been independently validated by numerous studies (e.g., Dussias \& Cramer Scaltz, 2008; Garnsey, Pearlmutter, et al., 1997; Wilson \& Garnsey, 2009). Crucially, Garnsey, Pearlmutter, et al. demonstrated a close correspondence between the classification of verbs as having a DO bias, as having an SC bias, and as being equi (EQ)-biased and the linguistic behavior of participants in a self-paced reading moving window experiment and an eyetracking study. ${ }^{1}$ To illustrate, when SC-biased verbs such as admit preceded a noun phrase - underlined in 1 below - that was syntactically ambiguous between a DO and an embedded subject, participants assigned it the role of embedded subject, a finding identical with the behavior of verbs classified as SC biased. Conversely, when direct-object bias verbs (e.g., maintain) preceded the ambiguous noun phrases, participants assigned them the role of DO.

1. The ticket agent admitted (maintained) the mistake might have been caught.

The Garnsey et al. norms receive further independent validation from a recent cross-corpus study. Using the verb subcategorization frequencies of 281 verbs from the Touchstone Applied Science Associates corpus (Zeno, Ivens, Millard, \& Duvvuri, 1995) and the Brown corpus (Francis \& Kučera, 1982), Gahl et al. (2004) reported a high degree of consistency between their norming results and the data from 10 other sources, among which were the Garnsey et al. norms. Hare et al. (2004) also showed that their sense-based verb norms, which were derived from corpus classifications, corresponded well with the experimental results reported in Garnsey, Pearlmutter, et al. (1997), a finding that adds further independent validity to the Garnsey et al. norms.

The 81 verbs were translated into Spanish using the Collins Dictionary, Español-Inglés/English-Spanish (Sinclair Knight, 2000), and the resulting translations were subsequently verified by a Spanish-English translator. An additional 54 Spanish cognate verbs, selected from Nash's (1997) Spanish-English cognate dictionary, were also normed. Using these 135 verbs $(81+54)$, two lists were created. List 1 contained the 81 target verbs and 49 fillers (e.g., dative verbs, intransitive verbs, and verbs that subcategorized for prepositional phrases) of similar length and number of syllables. Fillers were included in order to discourage participants from limiting their completions predominantly to DOs and SCs. List 2 included the 54 cognate verbs and a subset of 46 verbs from the 81 verbs included in List 1 . Because List 1 and List 2 would be administered to different groups of monolingual Spanish participants, the 46 verbs in List 2 were included to check for consistency in the participants' responses between the two lists.

Twenty randomized files were created, 10 for each list. Each file contained the target and filler verbs in their past tense form embedded in a sentence fragment headed by a subject (always a proper name).

Procedure. Usage frequencies were obtained using the sentence completion task described in Garnsey, Pearlmutter, et al. (1997). Participants were instructed to read each sentence fragment silently and to fill in a completion by hand next to the corresponding verb. They were told that there were no constraints on the length of their completions and that the resulting sentence needed to be grammatically correct and semantically plausible. No other instructions were provided.

Data collection took place over the course of 3 years. Data for List 1 were collected twice during Year 1 and twice during Year 2. List 1 was administered to a total of 464 Spanish monolingual speakers. List 2 was administered to an additional group 111 monolingual Spanish speakers during Year 3.

\section{Results}

Participants' responses to a verb were coded in three categories: DO completions, SC completions, and other completions. This last category included prepositional phrases, infinitivals, and completions headed by relative pronouns such as lo que (that which). Average responses in each category were computed. Participants often failed to provide a completion for a given verb, particularly if it occurred toward the bottom of the list. For these cases, as well as for cases in which the responses were illegible, the trial was coded as missing, and the number of participants included for the particular verb was reduced by 1 .

As was stated earlier, norms for the 81 Spanish verbs in Experiment 1 (List 1) were collected at different times. Therefore, correlations between DO average responses and between SC responses were computed to determine whether the completions provided for each verb were consistent across time. Results showed a significant and positive correlation ( $p<.0001$; see Tables 1 and 2$)$.

In addition, we conducted a second correlation analysis that compared responses to the 46 verb entries that were

Table 1

Correlations Between 81 Verbs for Year 1 and Year 2: Direct Object Completions

\begin{tabular}{cccc}
\hline & \multicolumn{3}{c}{ Direct } \\
\cline { 2 - 4 } & $\begin{array}{c}\text { Year 1 } \\
\text { (Time 2) }\end{array}$ & $\begin{array}{c}\text { Year 2 } \\
\text { (Time 1) }\end{array}$ & $\begin{array}{c}\text { Year 2 } \\
\text { (Time 2) }\end{array}$ \\
\hline Year 1 (Time 1) & .97 & .91 & .85 \\
Year 2 (Time 2) & & .86 & .81 \\
Year 1 (Time 1) & & & .92 \\
\hline
\end{tabular}

Note-All correlations are significant $(p<.0001)$.

Table 2

Correlations Between 81 Verbs for Year 1 and Year 2: Sentential Complement Completions

Sentential Complement Completions

Year $1 \quad$ Year 2 Year 2

(Time 2) (Time 1) (Time 2)

$\begin{array}{llll}\text { Year } 1 \text { (Time 1) } & 92 & 78 & 74\end{array}$

$\begin{array}{lll}\text { Year } 2 \text { (Time 2) } & .73 & .78\end{array}$

Year 1 (Time 1) $\quad .81$

Note-All correlations are significant $(p<.0001)$ 
Table 3

Correlations Between 46 Verbs for Year 1, Year 2, and Year 3: Direct Object Completions

\begin{tabular}{lcccc}
\hline & \multicolumn{4}{c}{ Direct Object Completions } \\
\cline { 2 - 5 } & $\begin{array}{c}\text { Year 1 } \\
\text { (Time 2) }\end{array}$ & $\begin{array}{c}\text { Year 2 } \\
\text { (Time 1) }\end{array}$ & $\begin{array}{c}\text { Year 2 } \\
\text { (Time 2) }\end{array}$ & Year 3 \\
\hline Year 1 (Time 1) & .96 & .86 & .79 & .84 \\
Year 2 (Time 2) & & .81 & .76 & .78 \\
Year 1 (Time 1) & & & .88 & .94 \\
Year 2 (Time 2) & & & & .85 \\
\hline
\end{tabular}

Note-All correlations are significant $(p<.0001)$.

Table 4

Correlations Between 46 Verbs for Year 1, Year 2, and Year 3: Sentential Complement Completions

\begin{tabular}{lcccc}
\hline & \multicolumn{3}{c}{ Sentential Complement Completions } \\
\cline { 2 - 5 } & $\begin{array}{c}\text { Year 1 } \\
\text { (Time 2) }\end{array}$ & $\begin{array}{c}\text { Year 2 } \\
\text { (Time 1) }\end{array}$ & $\begin{array}{c}\text { Year 2 } \\
\text { (Time 2) }\end{array}$ & Year 3 \\
\hline Year 1 (Time 1) & .93 & .79 & .65 & .65 \\
Year 2 (Time 2) & & .73 & .62 & .58 \\
Year 1 (Time 1) & & & .82 & .77 \\
Year 2 (Time 2) & & & & .75 \\
\hline
\end{tabular}

Note-All correlations are significant $(p<.0001)$.

common to List 1 and List 2. When responses were compared across the three different years in which the data were collected (i.e., Year 1 and Year 2 for List 1, and Year 3 for List 2), the results again showed a significant and positive correlation $(p<.0001)$. Table 3 provides the results for verbs completed with a DO continuation, and Table 4 provides results for verbs completed with an SC continuation. Taken together, the findings suggest that participants' responses were highly consistent across time. Therefore, in subsequent analyses, we collapsed the responses for each verb.

Following criteria frequently used in psycholinguistic verb bias studies (Garnsey, Pearlmutter, et al., 1997; Trueswell et al., 1993; Wilson \& Garnsey, 2009), a verb was classified as having a DO bias if it was used at least twice as often with a DO completion as with an SC completion and as having an SC bias if there were at least twice as many SC completions as DO ones. Verbs were classified as EQ biased if the difference between DO and SC completions was not greater than $15 \%$. Remaining verbs were classified as no bias. ${ }^{2}$ We chose a coding method that relied on relative frequencies (e.g., Garnsey, Lotocky, et al., 1997; Trueswell et al., 1993), rather than absolute frequencies (e.g., Merlo, 1994), for two reasons. First, we wanted to generate a set of verb bias norms in Spanish that would be comparable to existing English norms. Second, Gahl et al. (2004, Experiment 4) presented evidence suggesting that only the relative criterion for classifying verb bias could account for some of the results reported in a number of psycholinguistic studies. Therefore, we opted for coding our verbs using the relative method.

From the total 135 verbs normed, $50 \%$ were DO biased, $23 \%$ were EQ biased, $16 \%$ were SC biased, and $11 \%$ were no bias. Appendix A (in the online supplemental materials) shows the results for the 135 verbs from List 1 and List 2 (i.e., the 81 Spanish verbs translated from the Garnsey et al. norms and the additional 54 Spanish-English cognate verbs). The first column lists whether the verb was included in the Garnsey et al. norms. Verbs accompanied by a "No" label belong to the group of 54 Spanish cognate verbs. The next column lists the verb entries. The next three columns provide the percentages of DO responses, $\mathrm{SC}$ responses, and other responses (DO average response, $M=.55, S D=$ .31 ; SC average response, $M=.26, S D=.23$, and other average responses, $M=.19, S D=.25)$. Next are the resulting bias for each verb and total number of responses for each entry. When available, we also provide the lexical frequency (Freq) from Alameda and Cuetos (1995).

For our analyses, we focused mainly on the DO/SC classification (instead of all four possible classifications) because of its theoretical importance in current sentence processing literature. Correlation analyses comparing the results of the 81 Spanish verbs with the equivalent English translations from the Garnsey et al. norms were positively significant (DO average, $r=.44, p<.0001$, and SC average, $r=.41, p<.001)$. Establishing whether there are cross-linguistic differences in verb bias, particularly between SC-biased and DO-biased verbs in Spanish and English, is critical for scholars who wish to identify how the lexicon and grammar of the bilingual's two languages produce mutual influences and how competition between the two linguistic systems is resolved. Hence, a 2 (language: Spanish vs. English) $\times 2$ (type: DO vs. SC) ANOVA on the average responses was computed. Neither a main effect of language $(F<1)$ nor an interaction between language and type $(F<1)$ was found. However, the results showed a main effect of type $[F(1,80)=10.453, p<.01]$, such that DO responses $(M=.46, S D=32)$ were more frequent than SC responses $(M=.31, S D=23)$, as shown by comparing responses in Spanish $[t(80)=2.72, p<$ $.01]$ and in English $[t(80)=2.81, p<.01]$ and when comparing Spanish with English $[t(80)=2.88, p<.01]$ and English with Spanish $[t(80)=-3.15, p<.01]$.

When bias alone was taken into account, $49 \%$ of the verbs showed a different bias in Spanish and English. However, the vast majority of these involved cases in which a verb changed between EQ and either DO or SC bias. Reverses in bias between Spanish and English also occurred but were considerably fewer. Three verbs in Spanish were DO, whereas their English translations were SC: asumió (assumed), calculó (figured), and indicó (indicated). In four cases, verbs in Spanish were SC and in English were DO: advirtió (warned), afirmó (asserted), aseguró (insured), and se acordó (remembered). Appendix B (in the supplemental materials) displays the usage frequencies for each of the 81 verbs in Spanish and English.

\section{STUDY 2 \\ Spanish-English Bilinguals}

\section{Method}

Participants. One hundred Spanish-English bilinguals from the University of Granada were recruited. Participants were junior and senior undergraduate students in English philology or translation and interpretation. All had lived in an English-speaking environment for an average of 3 months and considered themselves proficient speakers of English. Proficiency was also assessed using the Cam- 
bridge Quick Placement Test. Only those participants who scored 3 or higher out of a possible 5 were included in the study. Six participants were excluded because they did not meet the criteria. The remaining 94 participants were included in the data analyses.

Materials. Norms for the 100 verbs listed in the Garnsey et al. norms were collected in English. These norms were gathered to determine whether L2 speakers of English learn the subcategorization biases of verbs in their L2 and to find out the strategies they employ in cases where knowledge of the L2 biases is lacking. In addition to the 100 verbs, 18 new English verbs with length and number of syllables similar to those of the target verbs, as well as the English translations of 12 verbs from List 2, were included as fillers, for a total of 130 English verbs.

Ten randomized lists were created. Each list contained the target and filler verbs in their preterit forms embedded in a sentence fragment headed by a subject (always a proper name).

Procedure. The procedure was the same as that in Study 1.

\section{Results}

Results are summarized in Appendix C in the supplemental materials: The overall mean of DO responses was $.60(S D=.33)$, of $S C$ responses was $.27(S D=.26)$, and of other responses was $.11(S D=.21)$. From the 130 verbs included in Study 2, we selected the 100 verbs included in the Garnsey et al. norms and compared the responses provided by the Spanish-English bilinguals with those reported in the Garnsey et al. norms in order to examine the degree to which the bilinguals' responses reflected those of the native English speakers. Significant positive correlations were found between DO averages $(r=$ $.61, p<.0001)$ and SC averages $(r=.67, p<.0001)$ for the two groups of participants. A 2 (language: bilinguals vs. English monolinguals) $\times 2$ (type: DO vs. SC) ANOVA on average responses revealed a main effect of language $[F(1,99)=11.596, p<.01]$, a main effect of type $[F(1,99)=21.001, p<.0001]$, and an interaction between language and type $[F(1,99)=8.246, p<.01]$. Although there were no significant differences between bilinguals and monolinguals in the number of SC responses produced $[t(99)=-1.149, p>.2]$, DO responses were more frequently produced by bilinguals than by English monolinguals $[t(99)=3.568, p<.001]$.

For each of the 100 verbs, we also compared the verb bias classification that resulted from our bilingual norming study with that in Garnsey, Pearlmutter, et al.'s (1997) norming study. This was done to determine sources of variation between the two groups of speakers that might highlight the difficulties encountered when bilinguals are learning verb bias information in the L2. Results indicate that 39 of the 100 English verbs differed in their verb bias assignment for the two groups of speakers. Perhaps most interestingly, 11 of the 39 responses were cases in which bilinguals' usage frequencies in English differed from the biases reported in the Garnsey et al. norms but also from our monolingual Spanish norms. For example, mentioned was classified as EQ biased in Garnsey, Pearlmutter, et al. (1997), as no bias in our Spanish data, but as DO biased in the bilingual norming study. Biases for these 11 verbs in the bilingual norms were almost evenly distributed between EQ bias and DO bias, with only one $\mathrm{SC}$ bias and one no-bias verb classification. An additional set of 11 verbs with the same bias in English and Spanish turned out to have a different bias in the bilingual norms (e.g., hinted is SC biased in English and Spanish, but DO biased for bilingual speakers). For this set of verbs, a little over half were classified as DO biased, and the rest as $\mathrm{SC}$ biased or no bias. Although it is highly speculative, the fact that for these 22 cases no single verbal argument completion was used across the board by the bilingual participants seems to suggest that their verbal completions were not characterized by the application of a particular strategy (e.g., providing simple DO completions) but most likely reflected the frequencies with which each verb was used with each particular complement in the English input available to them. Finally, the remaining 10 of the 39 cases showed the clearest evidence of transfer from the L1 Spanish (e.g., confirmed is DO biased in the Garnsey et al. norms, but EQ biased in our Spanish norms and in the bilingual norms), suggesting that in some cases, bilinguals were influenced by L1 biases when providing completions in their L2.

Sixty-one verbs overlapped in bias between our bilingual norms and those reported in the Garnsey et al. norms. Of these, 30 verbs shared bias with Spanish (e.g., accepted, admitted, asked), and 19 were different from Spanish. The latter result suggests that bilinguals are able to learn the frequency usage of verbs in their L2, even when immersed in the native language environment. This was true for cases in which the verb was EQ biased in Spanish but SC biased (e.g., wished) or DO biased (e.g., recognized) in English, as well as for cases in which there was a reverse in bias between the L1 and the L2 (e.g., insured and warned).

\section{CONCLUSION}

The present study argues for the need to document verb bias estimates in a variety of languages. Our main point is that verb bias norms, which are rare for languages other than English, are essential to conducting cross-linguistic and bilingual studies of sentence comprehension that test the predictions of competing models of sentence processing. Within this context, we addressed two main questions. First, are verb norms collected at a specific time reliable? We focused on this question because of the central role that verb bias norms play in testing competing models of sentence processing. If verb-specific information is to be used as a source to predict psycholinguistic experimental results of sentence comprehension, it is necessary to establish whether verb bias norms are true estimates of the underlying knowledge that speakers presumably use during on-line comprehension. To address this question, verb bias normative data was collected over the course of 3 years for a set of 81 Spanish verbs. The Spanish verbs were translations of English verbs used in a previous verb bias norming study of American English conducted by Garnsey, Lotocky, et al. (1997). A group of 575 monolingual university students from Spain provided completions for each verb. One significant feature of our findings is the correlation in participants' responses across the dif- 
ferent times at which data were collected. The implication of this finding for theory building is encouraging, because a highly reliable set of norms strengthens experimental findings relevant to theoretical issues being debated in the sentence processing literature. Another important result is the distribution of verb subcategorization frequencies between Spanish and English; only about half of the verbs normed share bias in the two languages. The availability of a corpus containing verbs with same and different biases will enable researchers interested in studying bilingual language processing to construct experiments in which verb bias between a bilingual's two languages is examined in order to study lexical effects on sentence processing.

With our second question, we investigated whether the knowledge of verb frames and their frequencies is similar for monolingual and bilingual speakers. Ninety-four Spanish-English bilinguals, also native speakers of Peninsular Spanish, provided completions in English for the complete set of 100 verbs normed in Garnsey, Lotocky, et al. (1997), whose norms were chosen because they are a particularly useful source for investigating cross-language activity in bilinguals, given that they contain a high number of English verbs that are cognate with Spanish. Here, we found that bilingual participants immersed in their L1 were able to learn verb bias information specific to the L2. We also noted that when bias did not match between the bilinguals and English monolinguals, bilinguals did not invariably transfer verb bias information from the L1 or opt for a strategy of supplying a syntactically simpler complement (e.g., a DO complement) for the verb. Instead, we observed a range of responses that can better be accounted for if we assume that they reflect the bilinguals' ability to tune into the usage frequencies of verbs in the L2 and to extract information from the English input to which they are exposed. A question for future research is whether bilinguals will behave similarly in contexts in which sentence processing in the L2 is examined as it unfolds in real time (e.g., Dussias \& Cramer Scaltz, 2008).

To conclude, to our knowledge both sets of norms constitute the first attempt to provide verb bias information for a group of verbs for which norms are available in English. We believe that these norms will enhance the limited research of cross-linguistic studies and bilingual studies of verb bias in the sentence processing literature.

\section{AUTHOR NOTE}

The writing of this article was supported in part by National Science Foundation Grant BCS-0821924 to P.E.D. and C.G. Our special thanks to Susan Garnsey for allowing us to print her unpublished English verb norms. Many thanks also to Tracey Cramer Scaltz for her valuable help during data collection and coding. All errors remain our own. Correspondence concerning this article should be addressed to P. E. Dussias, Department of Spanish, Italian, and Portuguese, Penn State University, 231 Burrowes Building, University Park, PA 16802 (e-mail: pdussias@psu.edu).

\section{REFERENCES}

Abutalebi, J., CapPa, S. F., \& Perani, D. (2005). What can functional neuroimaging tell us about the bilingual brain? In J. Kroll \& A. M. B. de Groot (Eds.), Handbook of bilingualism: Psycholinguistic perspectives (pp. 497-515). Oxford: Oxford University Press.

Alameda, J. R., \& Cuetos, F. (1995). Diccionario de frecuencias de las unidades lingüísticas del castellano. Oviedo: Servicio de Publicaciones de la Universidad de Oviedo.

Bates, E., Friederici, A. D., \& Wulfeck, B. (1987). Comprehension in aphasia: A cross-linguistic study. Brain \& Language, 32, 19-67.

Blumenfeld, H. K., \& Marian, V. (2005). Covert bilingual language activation through cognate word processing: An eye-tracking study. In Proceedings of the Twenty-Seventh Annual Meeting of the Cognitive Science Society (pp. 286-291). Mahwah, NJ: Erlbaum.

Dussias, P. E. (2003). Syntactic ambiguity resolution in L2 learners: Some effects of bilinguality on L1 and L2 processing strategies. Studies in Second Language Acquisition, 25, 529-557.

Dussias, P. E., \& Cramer Scaltz, T. R. (2008). Spanish-English L2 speakers' use of subcategorization bias information in the resolution of temporary ambiguity during second language reading. Acta Psychologica, 128, 501-513.

Dussias, P. E., \& Sagarra, N. (2007). The effect of exposure on syntactic parsing in Spanish-English bilinguals. Bilingualism, Language \& Cognition, 10, 101-116.

Druks, J., \& Marshall, J. C. (1995). When passive are easier than actives: Two case studies of aphasic comprehension. Cognition, 55, 311-331.

Duyck, W., van Assche, E., Drieghe, D., \& Hartsuiker, R. J. (2007). Visual word recognition by bilinguals in a sentence context: Evidence for nonselective access. Journal of Experimental Psychology: Learning, Memory, \& Cognition, 33, 663-679.

Elston-Güttler, K. E., Gunter, T. C., \& Kotz, S. A. (2005). Zooming into L2: Global language context and adjustment affect processing of interlingual homographs in sentences. Cognitive Brain Research, 25, 57-70

Ferreira, F., \& Henderson, J. M. (1990). Use of verb information in syntactic parsing: Evidence from eye movements and word-by-word self-paced reading. Journal of Experimental Psychology: Learning, Memory, \& Cognition, 16, 555-568.

Francis, W., \& KuČERA, H. (1982). Frequency analysis of English usage: Lexicon and grammar. Boston: Houghton Mifflin.

Frazier, L. (1987). Sentence processing: A tutorial review. In M. Coltheart (Ed.), Attention and performance XII: The psychology of reading (pp. 559-586). Hillsdale, NJ: Erlbaum.

FrAZIER, L. (1990). Exploring the architecture of the languageprocessing system. In G. T. M. Altmann (Ed.), Cognitive models of speech processing: Psycholinguistic and computational perspectives (pp. 409-433). Cambridge, MA: MIT Press.

Frazier, L., \& Clifton, C., Jr. (1996). Construal. Cambridge, MA: MIT Press.

FrAZIER, L., \& Fodor, J. D. (1978). The sausage machine: A new twostage parsing model. Cognition, 6, 291-325.

FRAZIER, L., \& RAYNER, K. (1982). Making and correcting errors during sentence comprehension: Eye movements in the analysis of structurally ambiguous sentences. Cognitive Psychology, 14, 178-210.

Frenck-Mestre, C., \& Pynte, J. (1997). Syntactic ambiguity resolution while reading in second and native languages. Quarterly Journal of Experimental Psychology, 50A, 119-148.

Friederici, A. D., \& Graetz, P. A. M. (1987). Processing passive sentences in aphasia: Deficits and strategies. Brain \& Language, 30, 93 105.

Gahl, S., JuRAFSKY, D., \& Roland, D. (2004). Verb subcategorization frequencies: American English corpus data, methodological studies, and cross-corpus comparisons. Behavior Research Methods, Instruments, \& Computers, 36, 432-443.

Gahl, S., Menn, L., Ramsberger, G., Jurafsky, D., Elder, E., ReWEGA, M., \& Audrey, H. (2003). Syntactic frame and verb bias in aphasia: Plausibility judgments of undergoer-subject sentences. Brain \& Cognition, 53, 223-228.

Garnsey, S. M., Lotocky, M. A., Pearlmutter, N. J., \& Myers, E. M. (1997). Argument structure frequency biases for 100 sentencecomplement-taking verbs. Unpublished manuscript, University of Illinois at Urbana-Champaign.

Garnsey, S. M., Pearlmutter, N. J., Myers, E. M., \& Lotocky, M. A (1997). The contributions of verb bias and plausibility to the comprehension of temporarily ambiguous sentences. Journal of Memory \& Language, 37, 58-93.

Hare, M., McRae, K., \& Elman, J. L. (2003). Sense and structure: 
Meaning as a determinant of verb subcategorization preferences. Journal of Memory \& Language, 48, 281-303.

Hare, M., McRae, K., \& Elman, J. L. (2004). Admitting that admitting verb sense into corpus analyses makes sense. Language \& Cognitive Processes, 19, 181-224.

JARED, D., \& Kroll, J. F. (2001). Do bilinguals activate phonological representations in one or both of their languages when naming words? Journal of Memory \& Language, 44, 2-31.

KenNison, S. M. (2001). Limitations on the use of verb information in sentence comprehension. Psychonomic Bulletin \& Review, 8, 132-138.

Kennison, S. M. (2009). The use of verb information in parsing: Different statistical analyses lead to contradictory conclusions. Journal of Psycholinguistic Research, 38, 363-378.

Kroll, J. F., \& DE Groot, A. M. B. (EDS.) (2005). Handbook of bilingualism: Psycholinguistic perspectives. Oxford: Oxford University Press.

Kroll, J. F., \& Stewart, E. (1994). Category interference in translation and picture naming: Evidence for asymmetric connections between bilingual memory representations. Journal of Memory \& Language, 33, 149-174.

Libben, M., \& Titone, D. (2009). Bilingual lexical access in context: Evidence from eye movements during reading. Journal of Experimental Psychology: Learning, Memory, \& Cognition, 35, 381-390.

Luzzatti, C., Toraldo, A., Guasti, M. T., Ghirardi, G., Lorenzi, L., \& Guarnaschelli, C. (2001). Comprehension of reversible active and passive sentences in "agrammatism." Aphasiology, 15, 419-444.

MacDonald, M. C. (1994). Probabilistic constraints and syntactic ambiguity resolution. Language \& Cognitive Processes, 9, 157-201.

MacDonald, M. C., Pearlmutter, N. J., \& Seidenberg, M. S. (1994a). The lexical nature of syntactic ambiguity resolution. Psychological Review, 101, 676-703.

MacDonald, M. C., Pearlmutter, N. J., \& Seidenberg, M. S. (1994b). Syntactic ambiguity resolution as lexical ambiguity resolution. In K. Rayner (Ed.), Perspectives on sentence processing (pp. 123153). Hillsdale, NJ: Erlbaum.

MaCizo, P., \& BAJO, M. T. (2006). Reading for understanding and reading for translation: Are they equal? Cognition, 99, 1-34.

Marian, V., \& SPIVEy, M. (2003). Bilingual and monolingual processing of competing lexical items. Applied Psycholinguistics, 24, 173-193.

MerLo, P. (1994). A corpus-based analysis of verb continuation frequencies for syntactic processing. Journal of Psycholinguistic Research, $4,435-447$.

Miyake, A., Carpenter, P., \& Just, M. A. (1994). A capacity approach to syntactic comprehension disorders: Making normal adults perform like aphasic patients. Cognitive Neuropsychology, 11, 671-717.

NASH, R. (1997). NTC's dictionary of Spanish cognates thematically organized. New York: McGraw-Hill.

Rayner, K., Carlson, M., \& Frazier, L. (1983). The interaction of syntax and semantics during sentence processing: Eye movements in the analysis of semantically biased sentences. Journal of Verbal Learning \& Verbal Behavior, 22, 358-374.

Roland, D., Jurafsky, D., Menn, L., Gahl, S., Elder, E., \& RidDOCH, C. (2000). Verb subcategorization frequency differences between business-news and balanced corpora: The role of verb sense. In Proceedings of the Association for Computational Linguistics (ACL2000) Workshop on Comparing Corpora (pp. 28-34). Hong Kong.

Sánchez-Casas, R. M., García-Albea, J. E., \& Davis, C. W. (1992). Bilingual lexical processing: Exploring the cognate/non-cognate distinction. European Journal of Cognitive Psychology, 4, 293-310.
Schwartz, A. I., \& Kroll, J. F. (2006). Language comprehension in bilingual speakers. In M. Traxler \& M. A. Gernsbacher (Eds.), Handbook of psycholinguistics (2nd ed., pp. 967-999). Amsterdam: Elsevier.

Schwartz, A. I., Kroll, J. F., \& Diaz, M. (2007). Reading words in Spanish and English: Mapping orthography to phonology in two languages. Language \& Cognitive Processes, 22, 106-129.

SinClair Knight, L. (Series ED.) (2000). Collins dictionary of EspañolInglés/English-Spanish (6th ed.). New York: HarperCollins.

St. John, M. F., \& Gernsbacher, M. A. (1998). Learning and losing syntax: Practice makes perfect and frequency builds fortitude. In A. F. Healy \& L. E. Bourne, Jr. (Eds.), Foreign language learning: Psycholinguistic studies on training and retention (pp. 231-255). Mahwah, NJ: Erlbaum.

Stowe, L., \& Sabourin, L. (2005). Imaging the processing of a second language: Effects of maturation and proficiency on the neural processes involved. International Review of Applied Linguistics in Language Teaching, 43, 329-353.

Trueswell, J. C., Tanenhaus, M. K., \& Kello, C. (1993). Verbspecific constraints in sentence-processing: Separating effects of lexical preference from garden-paths. Journal of Experimental Psychology: Learning, Memory, \& Cognition, 19, 528-553.

van Hell, J. G., \& de Groot, A. M. B. (2008). Sentence context affects lexical decision and word translation. Acta Psychologica, 128, 431-451.

van Hell, J. G., \& Dijkstra, T. (2002). Foreign language knowledge can influence native language performance in exclusively native contexts. Psychonomic Bulletin \& Review, 9, 780-789.

Weber, A., \& Paris, G. (2004). The origin of the linguistic gender effect in spoken-word recognition: Evidence from non-native listening. In K. Forbus, D. Gentner, \& T. Regier (Eds.), Proceedings of the 26th Annual Conference of the Cognitive Science Society (pp. 1446-1451). Mahwah, NJ: Erlbaum.

Wilson, M. P., \& GARNSEY, S. M. (2009). Making simple sentences hard: Verb bias effects in simple direct object sentences. Journal of Memory \& Language, 60, 368-392.

Zeno, S. M., Ivens, S. H., Millard, R. T., \& Duvvuri, R. (1995). The educator's word frequency guide. Brewster, NY: Touchstone.

\section{NOTES}

1. For example, anticipó (Appendix A) received an average of 52\% DO completions and $32 \%$ sentential object completions. Because the difference between the two values was not smaller than $15 \%$, the verb was classified as "no bias."

2. Note that of the 100 original verbs in Garnsey, Lotocky, et al. (1997), verb bias data for 56 verbs are published in the appendices of Garnsey, Pearlmutter, et al. (1997) and Wilson and Garnsey (2009). With permission from S. Garnsey, we provide the norms of the remaining verbs in this article.

\section{SUPPLEMENTAL MATERIALS}

Appendixes A-C discussed in this article may be downloaded from http://brm.psychonomic-journals.org/content/supplemental.

(Manuscript received November 10, 2009; revision accepted for publication May 23, 2010.) 